\title{
We need to talk about why we don't talk about exercise!
}

\author{
Fabrício Braga da Silva ${ }^{1,2,3}$
}

Laboratório de Performance Humana, ${ }^{1}$ Rio de Janeiro, $R J$ - Brazil

Casa de Saúde São José, ${ }^{2}$ Rio de Janeiro, RJ - Brazil

Confederação Brasileira de Triathlon, ${ }^{3}$ Vila Velha, ES - Brazil

Editorial referring to the article: Effect of Physical Training on Nitric Oxide Levels in Patients with Arterial Hypertension: An Integrative Review

We usually avoid subjects that make us feel uncomfortable. As in general these subjects are those we cannot deal with, the consequences of such omission can be really bad. Problems with our children are classical examples of topics we avoid. Published in 2003, "We Need to Talk About Kevin" is a novel written by Lionel Shriver, adapted to the big screen in 2011. The film addresses the vicious cycle of problems caused by the mother who neglects her child with overt psychopathy, culminating in a catastrophe. In this fiction, avoiding the subject cost the lives of many people.

This introductory metaphor was the preamble to the following question: based on available evidence, why do we not have proper conversation about exercise with our patients? Why is physical exercise little addressed in medical visits? Why are healthcare providers not concerned about individual and collective consequences of physical inactivity?

It is, of course, nothing new to affirm that physical inactivity is harmful to health, but at least I bring current information on that - physical inactivity accounts for $7.2 \%$ of premature deaths annually. ${ }^{1}$ In other words, every year, $7.2 \%$ of deaths would be avoided if people practiced 150 minutes of moderate-intensity exercise or 75 minutes of vigorous exercise per week (recommendation adopted by the authors). It is worth pointing out that, despite being published in 2022, these data do not include the COVID pandemic.

\section{Keywords}

Blood Pressure; Hypertension; Exercise; Physical Conditioning Human; Nitric Oxide; Endothelium Dependent Relaxing Factors.
Most of these deaths ( $69 \%$ or 2.5 million) are in middle-income countries like Brazil. Data from the Health Surveillance Secretary of the Brazilian Ministry of Health published in $2020^{2}$ showed that $47.2 \%$ (95\% CI $45.7-48.6 \%$ ) of Brazilian people are insufficiently physically active. In addition, 14.9\% (95\%CI 13.9-15.9\%) of people are physically inactive, i.e., do not practice any physical exercise, and when the life stage where the risk of chronic diseases attributable to sedentary lifestyle is considered, this percentage is greater than $30 \%$.

The causes of taking such an unhealthy behavior like physical inactivity are multiple. The lack of a structured guidance by primary health care providers is only one of them. However, the problem will persist unless due attention is paid to it. It is to say that (collective) public policies aimed at physical inactivity will occur only if health professionals (individually) counsel their patients about regular physical activity. In the United States, counseling about exercising in primary care has increased, ${ }^{3}$ although the numbers are still modest (less than one third of medical consultations). Also, the reasons why physical activity is a topic neglected by healthcare professionals are many. ${ }^{4}$

A reduction in the risk of death associated to regular exercise, at doses recommended, is grounded on the fact that this practice has been shown to decrease the risk of diseases with the highest mortality, ${ }^{5}$ notably cardiovascular diseases.

Primary and secondary prevention of arterial hypertension is among the mechanisms by which exercise reduces cardiovascular morbidity. ${ }^{6}$ At the previously mentioned doses, exercise can cause a decrease in systolic pressure by $5-7 \mathrm{mmHg}$, and a reduction in mortality from coronary disease and stroke by $9 \%$ and $14 \%$, respectively. ${ }^{7}$

Mailing Address: Fabrício Braga da Silva

Laboratório de Performance Humana. Largo do Ibam, 1. Postal Code: 22271-070. Humaita, Rio de Janeiro - Brazil.

Email: fabriciobraga@uol.com.br 
The benefits of (aerobic and resistance) exercise on arterial pressure are linked to the modulation of the autonomous nervous system and of vascular function and structure. ${ }^{8}$ In the latter, the increase in nitric oxide (NO) bioavailability plays a very important role. Initially thought of as an atmospheric pollutant, NO was discovered in 1772 by the English chemist Joseph Priestly and it took more than 200 years for its role in the modulation of vascular dilator tone to be identified. ${ }^{9}$

In this issue of the IJCS, in a systematic review of 16 clinical trials, Facioli et al. ${ }^{10}$ evaluated the response to different exercise interventions on $\mathrm{NO}$ production and its impact on blood pressure. Thirteen studies showed an increase in NO production and 15 reported a reduction in blood pressure levels. Intervention was aerobic exercise in most of studies (11 of 16), and only three used high-intensity exercises. Despite the high heterogeneity among parameters of exercise intensity (60\% to $100 \%$ of maximum heart rate; $50 \%$ to $100 \%$ of maximum $\mathrm{VO}_{2}$ etc) and volume (20-60 minutes; 3-4 days per week; 6-24 weekduration), this seemed not to influence NO production.

In summary, the findings of Facioli et al., ${ }^{10}$ add to the mass of evidence that supports, explains, and details the benefits of regular exercise for human health.

\section{References}

1. Katzmarzyk PT, Friedenreich C, Shiroma EJ, Lee I-M. Physical inactivity and non-communicable disease burden in low-income, middle-income and high-income countries. Br J Sports Med 2022;56(2):101-106. doi: 10.1136/bjsports-2020-103640.

2. Brasil. Ministério da Saúde. Vigitel Brasil 2020. Brasília; 2021

3. Barnes PM, Schoenborn CA. Trends in adults receiving a recommendation for exercise or other physical activity from a physician or other health professional. NCHS Data Brief. 2012;(86):1-8. PMID: 22617014.

4. Meira DT, Gonçalves LG, Araújo LH, et al. Talk the talk and walk the walk! Association between Weekly Exercise Load and Knowledge about Recommendations for Fighting Innactivity. Int I Cardiovasc Sci 2019;32(5):473-80

5. Pedersen BK, Saltin B. Exercise as medicine - Evidence for prescribing exercise as therapy in 26 different chronic diseases. Scand J Med Sci Sport 2015;25:1-72. doi: 10.1111/sms.12581.
Every year, 2.5 million people die prematurely due to physical inactivity; any person is shocked by this number. However, being shocked is not synonym of taking action, which reminds me of another film, "Hotel Rwanda", which addresses the genocide of the Tutsi minority by the Hutu ethnic majority in 1994. In an excerpt from the film, the hotel manager Paul Rusesabagina (Don Cheadle), who saved more than 1,000 other refugees by sheltering them in the hotel, thanked the journalist Jack Daglish (Joaquin Phoenix), for shooting the footage and recording the atrocities his people suffered; he was certain that international help would come after the world sees those scenes. But then Daglish showed him the reality by telling him: "I think if people see this footage, they'll say Oh, my God, that's horrible. And then they'll go on eating their dinners".

The dissociation between outrage and attitude is proportional to the size of the problem to be solved. In order to talk properly about physical exercise with our patients, we first need to know why we do not talk about it to be able to help them incorporate exercise into their lives.

6. Pinckard K, Baskin KK, Stanford KI. Effects of Exercise to Improve Cardiovascular Health. Front Cardiovasc Med 2019;6:69. doi: 10.3389/ fcrm.2019.00069.

7. Alpsoy Ş. Exercise and Hypertension. Adv Exp Med Biol 2020;1228:153-67. doi: 10.1007/978-981-15-1792-1_10.

8. Sabbahi A, Arena R, Elokda A, Phillips SA. Exercise and Hypertension: Uncovering the Mechanisms of Vascular Control. Prog Cardiovasc Dis 2016;59(3):226-34. doi: 10.1016/j.pcad.2016.09.006.

9. Moncada S, Higgs EA. The discovery of nitric oxide and its role in vascular biology. Br J Pharmacol 2006;147 Suppl 1(Suppl 1):S193-201. doi: 10.1038/sj.bjp.0706458.

10. Facioli T de P, Buranello MC, Regueiro EMG, Basso-Vanelli RP, Durand M de T. Effect of Physical Training on Nitric Oxide Levels in Patients with Arterial Hypertension: An Integrative Review. Int J Cardiovasc Sci [Internet] 